Article

\title{
Silver Nanoparticle-Enhanced Resonance Raman Sensor of Chromium(III) in Seawater Samples
}

\author{
Nguyễn Hoàng Ly and Sang-Woo Joo * \\ Department of Chemistry, Soongsil University, Seoul 156-743, Korea; \\ E-Mail: nguyenhoangly2007@gmail.com \\ * Author to whom correspondence should be addressed; E-Mail: sjoo@ssu.ac.kr; \\ Tel./Fax: +82-2-820-0434.
}

Academic Editor: W. Rudolf Seitz

Received: 18 March 2015 / Accepted: 24 April 2015 / Published: 29 April 2015

\begin{abstract}
Tris(hydroxymethyl)aminomethane ethylenediaminetetraacetic acid (Tris-EDTA), upon binding $\mathrm{Cr}$ (III) in aqueous solutions at $\mathrm{pH} 8.0$ on silver nanoparticles (AgNPs), was found to provide a sensitive and selective Raman marker band at $\sim 563 \mathrm{~cm}^{-1}$, which can be ascribed to the metal-N band. UV-Vis absorption spectra also supported the aggregation and structural change of EDTA upon binding $\mathrm{Cr}$ (III). Only for $\mathrm{Cr}$ (III) concentrations above $500 \mathrm{nM}$, the band at $\sim 563 \mathrm{~cm}^{-1}$ become strongly intensified in the surface-enhanced Raman scattering spectra. This band, due to the metal-EDTA complex, was not observed in the case of $50 \mu \mathrm{M}$ of $\mathrm{K}^{+}, \mathrm{Cd}^{2+}, \mathrm{Mg}^{2+}, \mathrm{Ca}^{2+}, \mathrm{Mn}^{2+}, \mathrm{Co}^{2+}, \mathrm{Na}^{+}, \mathrm{Cu}^{2+}, \mathrm{NH}_{4}^{+}, \mathrm{Hg}^{2+}, \mathrm{Ni}^{2+}, \mathrm{Fe}^{3+}$, $\mathrm{Pb}^{2+}, \mathrm{Fe}^{2+}$, and $\mathrm{Zn}^{2+}$ ions. Seawater samples containing $\mathrm{K}, \mathrm{Mg}, \mathrm{Ca}$, and $\mathrm{Na}$ ion concentrations higher than $8 \mathrm{mM}$ also showed the characteristic Raman band at $\sim 563 \mathrm{~cm}^{-1}$ above $500 \mathrm{nM}$, validating our method. Our approach may be useful in detecting real water samples by means of AgNPs and Raman spectroscopy.
\end{abstract}

Keywords: Cr(III); EDTA; Raman spectroscopy; silver nanoparticles; seawater

\section{Introduction}

Recent developments in methodologies for the detection and quantitation of heavy metal ions in aqueous solutions, are now receiving much attention [1]. Nanoparticles have been introduced for sensing heavy metal ions in solutions [2]. In this study, a strong metal ion chelator of 
ethylenediaminetetraacetic acid (EDTA) was found to make the chelation/aggregation process reversible. Raman spectroscopy is currently the method of choice for detection of trace analysis and surface characterization [3,4]. Surface-enhanced Raman spectroscopy (SERS) has recently been used to detect trace amounts of several hazardous substances [5,6]. Ultra-sensitive detection of ions is feasible through the combination of aggregation-dependent noble metal nanoparticles (NPs) and probe material in the field of nanobioanalysis [7].

Trivalent chromium is used as a dietary supplement and a therapeutic agent to increase the sensitivity of insulin [8,9]. The quantification of $\mathrm{Cr}$ (III) in water has usually required conventional approaches of various analytical techniques [10-13]. Metal nanostructures have been recently introduced to detect chromium ions with a combination of several linker units including Tween 20 [14], glutathione [15], 11-mercaptoundecanoic acid [16], 5,5'-dithio-bis-(2-nitrobenzoic acid) [17,18], citric acid [19], and a series of heterotripodal receptors [20]. SERS detection of $\mathrm{Cr}^{3+}$ has been reported using AgNPs and lateral flow immunoassays [21]. The monothiocyanate complexes of $\mathrm{Cr}^{3+}$ were also investigated on the silver electrode by SERS [22].

EDTA has been used to detect various foreign ions [23,24]. EDTA is known to show a strong Raman signal at $40-500 \mathrm{~cm}^{-1}$ due to the metal-N stretching bands, with a complex of several ionic species [25-27]. In the present work, we have introduced EDTA, as a method of confirming dissimilar adsorption behaviors depending on the concentrations of $\mathrm{Cr}(\mathrm{III})$ in the complex that yields a prominent spectral intensity at $\sim 563 \mathrm{~cm}^{-1}$ on silver nanoparticles (AgNPs) at concentrations of Cr(III) higher than $500 \mathrm{nM}$. Infrared spectroscopy also supported a structural change of EDTA upon binding Cr(III). UV-Vis absorption spectra suggest that there should be a resonance electron transition for the EDTA-Cr(III) complex and the plasmonic shifts of AgNPs at 600 800 nm.

We report a $\mathrm{Cr}$ (III) detection method with a complex of EDTA and subsequent adsorption on AgNPs by means of resonance Raman spectroscopy using a He-Ne laser excitation at $633 \mathrm{~nm}$. Considering that the Environmental Protection Agency (EPA) regulation [1] for levels in drinking water of the $\mathrm{Cr}$ (III) ion is around $1.9 \times 10^{-6} \mathrm{M}$, our method may be useful in detecting harmful wastewater by means of AgNPs and SERS. The EDTA-Cr(III) complex could yield different SERS intensities on AgNPs. EDTA is found to be sensitive and selective in binding $\mathrm{Cr}(\mathrm{III})$ in aqueous AgNP solutions.

\section{Experimental Section}

\subsection{Chemicals}

$\mathrm{Cr}(\mathrm{III})$ and the other ionic substances of $\mathrm{NaCl}, \mathrm{KNO}_{3}, \mathrm{Mg}\left(\mathrm{NO}_{3}\right)_{2}, \mathrm{Ca}\left(\mathrm{NO}_{3}\right)_{2}, \mathrm{Cr}\left(\mathrm{NO}_{3}\right)_{3}, \mathrm{Mn}\left(\mathrm{NO}_{3}\right)_{2}$, $\mathrm{FeC}_{2} \mathrm{O}_{4}, \mathrm{Fe}\left(\mathrm{NO}_{3}\right)_{3}, \mathrm{Co}\left(\mathrm{NO}_{3}\right)_{2}, \mathrm{Ni}\left(\mathrm{NO}_{3}\right)_{2}, \mathrm{Cu}\left(\mathrm{NO}_{3}\right)_{2}, \mathrm{Zn}\left(\mathrm{NO}_{3}\right)_{2}, \mathrm{NH}_{4} \mathrm{NO}_{3}, \mathrm{Cd}\left(\mathrm{NO}_{3}\right)_{2}, \mathrm{Hg}\left(\mathrm{NO}_{3}\right)_{2}$, $\mathrm{Pb}\left(\mathrm{NO}_{3}\right)_{2}$, and $\mathrm{K}_{2} \mathrm{Cr}_{2} \mathrm{O}_{7}$ (or $\mathrm{Na}_{2} \mathrm{CrO}_{4}$ ) along with silver nitrate, sodium citrate, Tris-EDTA (pH 8.0), and EDTA acetic acid were purchased from Sigma Aldrich (St. Louis, MO, USA). The buffer solution of $\mathrm{pH} 4.0$ was purchased from Thermo Scientific (Waltham, MA, USA). The seawater samples were obtained from the Yellow Sea (Tae-an, Chungcheongnam-do, Korea). The citrate-stabilized silver colloidal substrates were synthesized by following the recipes in the literature [28]. 


\subsection{Equipment and Characterization Methods}

In order to observe the resonance processes and aggregation properties of AgNPs, UV-Vis absorption spectra were obtained using a Mecasys UV-3220PC spectrophotometer (Daejeon, Korea). The transmission electron microscope images of AgNPs were obtained using JEM-3010 and JEM-1010 microscopes from JEOL (Peabody, MA, USA). For Fourier transform infrared spectroscopy (FT-IR) data, a drop of the EDTA-Cr(III) solution sample was transferred onto a MIRacle ZnSe attenuated-total reflection accessory from Pike Technologies (Madison, WI, USA). The infrared spectra were obtained using a FT-IR 6700 spectrometer equipped with a narrow band $\mathrm{HgCdTe}$ detector at the cut-off of $800 \mathrm{~cm}^{-1}$ from Thermo Nicolet (Waltham, MA, USA). Raman spectra at the irradiation of $632.8 \mathrm{~nm}$ were obtained using the previous method [29]. The resonance Raman spectrum at $532 \mathrm{~nm}$ in comparison with off-resonance near-infrared Raman at $785 \mathrm{~nm}$ was obtained using a LabRam Aramis spectrometer from Horiba Jovin Yvon (Palaiseau, France). X-ray photoelectron (XPS) spectra were obtained using a Sigma Probe instrument from Thermo VG using an Al-K $\alpha$ monochromatic source.

\subsection{Sample Preparation}

For the SERS experiment, $10 \mu \mathrm{L} \mathrm{Cr}^{3+}(1 \mathrm{mM}$, in either distilled water or seawater) and $50 \mu \mathrm{L}$ EDTA (Tris-EDTA buffer solution, $\mathrm{pH}$ 8.0) were mixed and stirred for over $60 \mathrm{~min}$ at room temperature. Subsequently, $140 \mu \mathrm{L}$ of AgNPs were added to the mixture and the SERS spectra were observed. Seawater obtained from the Yellow Sea in Korea was checked by inductively coupled plasma optical emissions spectrometry (ICP-OES) with an ICAP-7400 analyzer from Thermo Scientific (Waltham, MA, USA) and a CETAC M-7500 mercury analyzer from Parma Company (Omaha, NE, USA). AgNPs-EDTA exhibited a selective turn-on Raman intensity response to $\mathrm{Cr}^{3+}$ in seawater $(50 \mu \mathrm{M})$. Response behaviors were observed for AgNPs-EDTA in the presence of various environmentally relevant metal ions. The Raman spectral features of AgNPs-EDTA-M ${ }^{\mathrm{n}+}$ were unchanged in the presence of $\mathrm{K}^{+}, \mathrm{Cd}^{2+}, \mathrm{Mg}^{2+}, \mathrm{Ca}^{2+}, \mathrm{Mn}^{2+}, \mathrm{Co}^{2+}, \mathrm{Na}^{+}, \mathrm{Cu}^{2+}, \mathrm{NH}_{4}^{+}, \mathrm{Hg}^{2+}, \mathrm{Ni}^{2+}, \mathrm{Fe}^{3+}$, $\mathrm{Pb}^{2+}, \mathrm{Fe}^{2+}$, and $\mathrm{Zn}^{2+}$ ions (all at concentrations of $50 \mu \mathrm{M}$ ). Of all the tested metal ions, only $\mathrm{Cr}^{3+}$ ion increased the Raman intensity in the presence of AgNPs-EDTA. For the XPS experiment, $1.0 \mathrm{~mL}$ of this mixture was put into a $1.5 \mathrm{~mL}$ centrifugal tube, the AgNPs-EDTA-Cr ${ }^{3+}$ was collected by centrifugation at $10,000 \mathrm{rpm}$ for $10 \mathrm{~min}$ at $4{ }^{\circ} \mathrm{C}$, and the supernatant ones were carefully removed up to a residual volume of $20 \mu \mathrm{L}$. The $20 \mu \mathrm{L}$ of AgNPs-EDTA- $\mathrm{Cr}^{3+}$ was then dropped onto a cover glass (size $5 \mathrm{~mm} \times 5 \mathrm{~mm}$ ) from Deckgläser (Sondheim/Rhön, Germany), and dried at $75{ }^{\circ} \mathrm{C}$ overnight, and the XPS spectra were then observed.

\section{Results and Discussion}

Figure 1a shows the photographic images and UV-Vis absorption spectra of EDTA-Cr(III). Upon binding $\mathrm{Cr}$ (III), the color changed to purple to increase the absorbance values at 500-700 $\mathrm{nm}$, including $633 \mathrm{~nm}$ of the excitation wavelength of the Raman experiments. Infrared spectra also suggested the structural change, as indicated in Figure 1b. The UV-Vis spectrum of EDTA appeared to be similar to the previous report [30]. The bands at 1622, 1522, and $1387 \mathrm{~cm}^{-1}$ can be ascribed to the 
$v(\mathrm{C}=\mathrm{O}), v_{\text {as }}\left(\mathrm{COO}^{-}\right)$, and $v_{\mathrm{s}}\left(\mathrm{COO}^{-}\right)$bands, respectively, [31]. The spectral changes suggest that more symmetric vibrations of the $\mathrm{COO}^{-}$band became stronger instead of the anti-symmetric vibration.

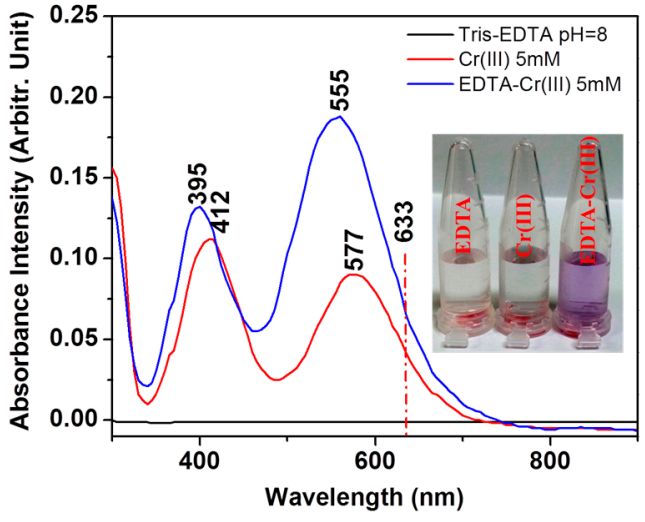

(a)

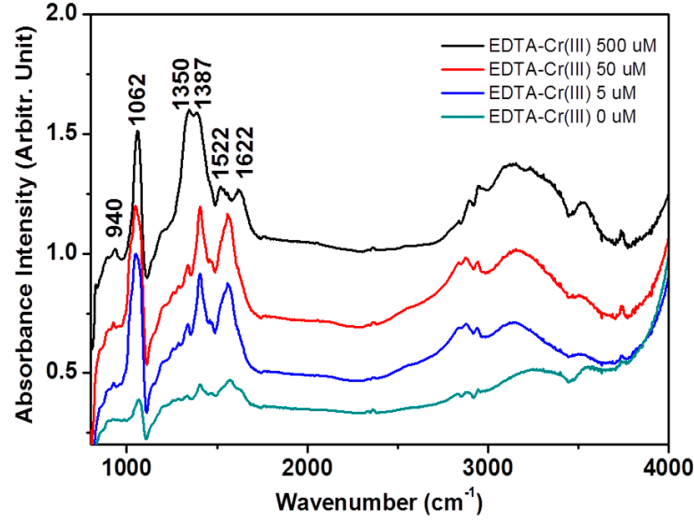

(b)

Figure 1. (a) UV-Vis spectra of ethylenediaminetetraacetic acid (EDTA), Cr(III), and EDTA-Cr(III). The inset shows the photo images. The dotted line indicates $633 \mathrm{~nm}$; (b) Fourier transform infrared (FT-IR) spectra of EDTA-Cr(III) at $800-4000 \mathrm{~cm}^{-1}$.

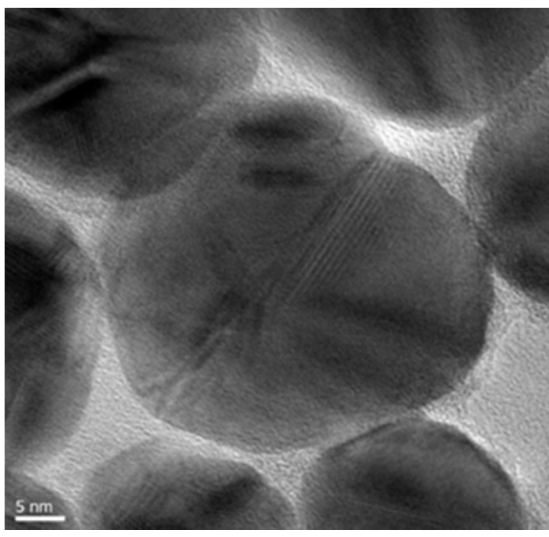

(a)

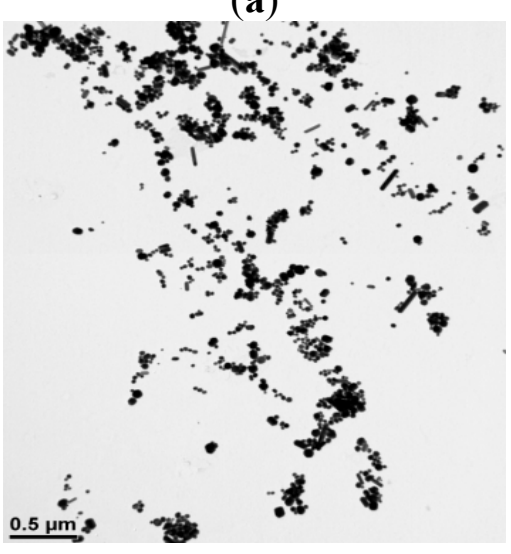

(c)

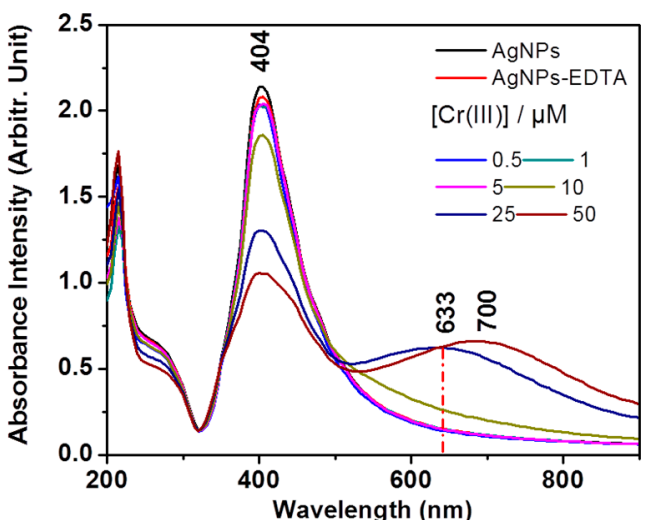

(b)

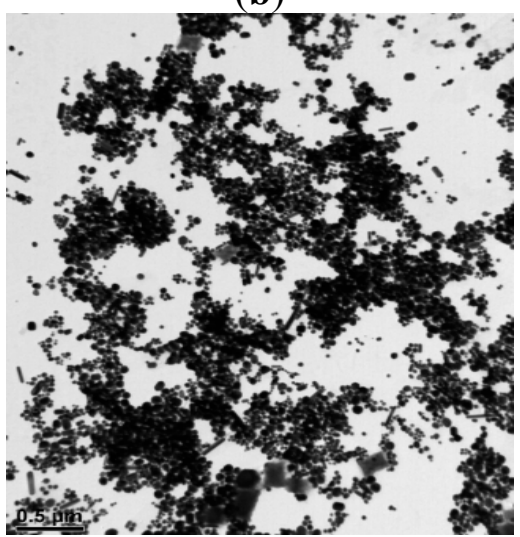

(d)

Figure 2. (a) TEM image of silver nanoparticles (AgNPs). The scale bar indicates $5 \mathrm{~nm}$; (b) UV-Vis absorption of AgNPs upon binding of EDTA with $\mathrm{Cr}$ (III). TEM images of aggregated AgNPs with EDTA at $\left[\mathrm{Cr}^{3+}\right]$ of (c) 0 and (d) $50 \mu \mathrm{M}$. The scale bars indicate $0.5 \mu \mathrm{M}$. 
Figure 2 shows a TEM image of prepared AgNPs. Upon the increase of $\mathrm{Cr}$ (III) in the complex, the UV-Vis spectra of AgNPs became red-shifted toward $600-800 \mathrm{~nm}$ to suggest the aggregation of AgNPs. These results indicate that EDTA with higher concentrations of $\mathrm{Cr}$ (III) could induce the plasmonic shift of the AgNPs. It has to be admitted that, it was not easy to compare the aggregation by the higher concentration of $\mathrm{Cr}^{3+}$ due to the dryness of the sample on the grid. The representative images depending on the concentrations of $\mathrm{Cr}^{3+}$ are compared in Figure 2c,d.

The increase of the absorbance at $633 \mathrm{~nm}$ should be more suitable for the surface-enhanced resonance Raman scattering (SERRS) experiments as performed in Figure 3. We attempted to observe the surface-enhanced resonance Raman spectra via $532 \mathrm{~nm}$ instead of $632.8 \mathrm{~nm}$. We could clearly see the vibrational band at $\sim 563 \mathrm{~cm}^{-1}$ at the excitation of $532 \mathrm{~nm}$, whereas this peak was not observed at $785 \mathrm{~nm}$. This result indicates that the strong Raman band at $\sim 563 \mathrm{~cm}^{-1}$ may be due to a resonance Raman effect via the absorption band at 500-600 $\mathrm{nm}$.

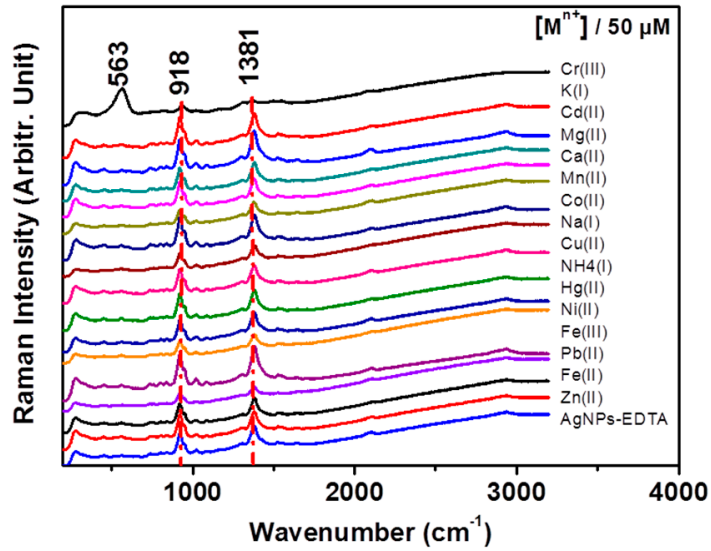

(a)

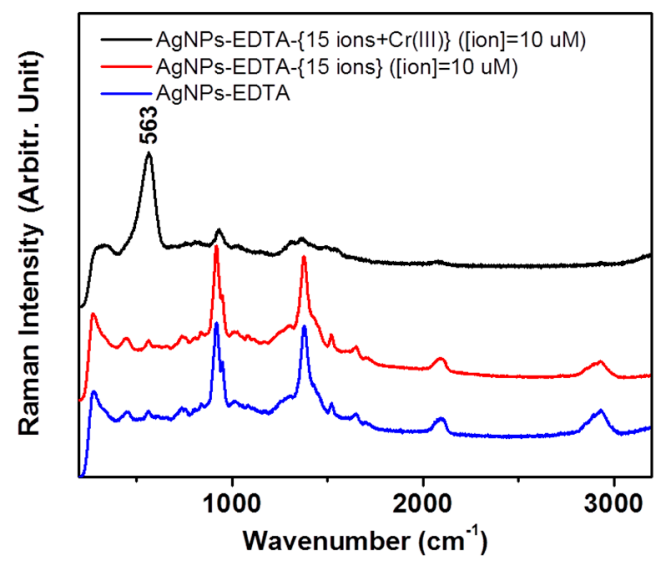

(c)

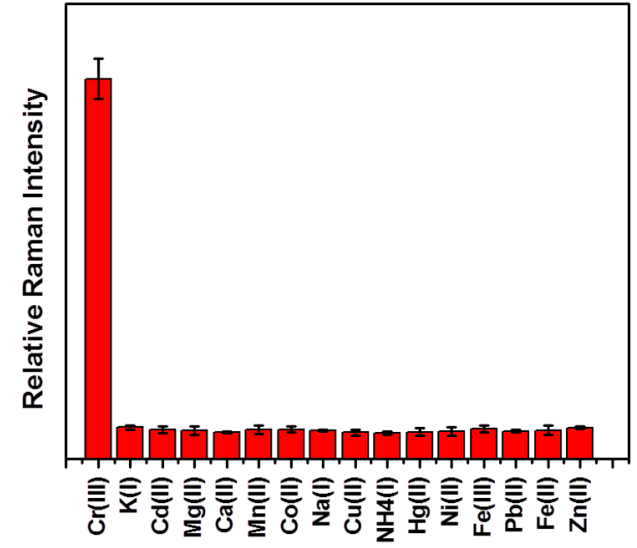

(b)

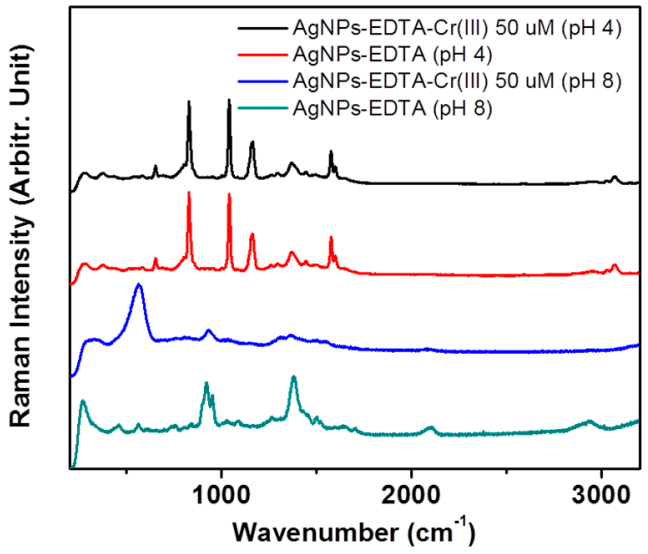

(d)

Figure 3. (a) Surface-enhanced Raman spectroscopy (SERS) spectra of detection of Cr(III) using Tris(hydroxymethyl)aminomethane (Tris)-EDTA on AgNPs. Selective tests were performed for $50 \mu \mathrm{M}$ of $\mathrm{Cr}^{3+}, \mathrm{K}^{+}, \mathrm{Cd}^{2+}, \mathrm{Mg}^{2+}, \mathrm{Ca}^{2+}, \mathrm{Mn}^{2+}, \mathrm{Co}^{2+}, \mathrm{Na}^{+}, \mathrm{Cu}^{2+}, \mathrm{NH}_{4}^{+}, \mathrm{Hg}^{2+}$, $\mathrm{Ni}^{2+}, \mathrm{Fe}^{3+}, \mathrm{Pb}^{2+}, \mathrm{Fe}^{2+}$, and $\mathrm{Zn}^{2+}$ ions; (b) Stick diagram of the intensities at $\sim 563 \mathrm{~cm}^{-1}$ with respect to those at $\sim 918 \mathrm{~cm}^{-1}$ versus 16 ionic species; (c) SERS spectra of the mixture of the 15 ions to test the competitive reactions; (d) Comparative SERS spectra of EDTA and EDTA-Cr ${ }^{3+}$ on AgNPs at $\mathrm{pH} 4.0$ and $\mathrm{pH}$ 8.0. 
Only the $\mathrm{Cr}^{3+}$ ion exhibited a unique intense peak at $\sim 563 \mathrm{~cm}^{-1}$ of the metal-N stretching band [25-27], along with the decrease of the two bands at 918 and $1381 \mathrm{~cm}^{-1}$. We also found that the mixture of the other 15 ions of $\mathrm{K}^{+}, \mathrm{Cd}^{2+}, \mathrm{Mg}^{2+}, \mathrm{Ca}^{2+}, \mathrm{Mn}^{2+}, \mathrm{Co}^{2+}, \mathrm{Na}^{+}, \mathrm{Cu}^{2+}, \mathrm{NH}_{4}^{+}, \mathrm{Hg}^{2+}, \mathrm{Ni}^{2+}, \mathrm{Fe}^{3+}, \mathrm{Pb}^{2+}, \mathrm{Fe}^{2+}$, and $\mathrm{Zn}^{2+}$ with the individual concentration of $10 \mu \mathrm{M}$ for each ion did not produce such a strong marker band as the case of $\mathrm{Cr}^{3+}$. When the 15 ions were mixed with $\mathrm{Cr}^{3+}$, the band at $563 \mathrm{~cm}^{-1}$ became more intensified as shown in Figure 3c. This result indicated that the other ions may not substantially interfere with the $\mathrm{Cr}^{3+}$ ion detection by competitive reactions at the high ion concentrations of $10 \mu \mathrm{M}$. We tested the $\mathrm{pH}$-dependent binding behaviors for $\mathrm{Cr}^{3+}$ at $\mathrm{pH} 4.0$ using EDTA acetic acid and the buffer solution at $\mathrm{pH}$ 4.0. We found that the Raman spectrum at $\mathrm{pH} 4.0$ became quite different from that at $\mathrm{pH}$ 8.0. Moreover, the Raman spectrum at $\mathrm{pH} 4.0$ did not produce such a peak of $563 \mathrm{~cm}^{-1}$ at $\mathrm{pH}$ 8.0, as compared in Figure 3d. This result indicated that the alkaline $\mathrm{pH}$ value of the AgNPs should be essential to producing the EDTA- $\mathrm{Cr}^{3+}$-induced spectral changes.

The two bands at 918 and $1381 \mathrm{~cm}^{-1}$, can be ascribed to the $v(\mathrm{C}-\mathrm{C})$ and $\mathrm{v}_{\mathrm{s}}\left(\mathrm{COO}^{-}\right)$bands, respectively, according to the literature [29]. The stronger enhancements of the $v s\left(\mathrm{COO}^{-}\right)$bands in the SERS spectrum in comparison with the FT-IR spectra may be due to the different selection rules. The two strong bands could be found at low concentrations of $\mathrm{Cr}$ (III) below either $500 \mathrm{nM}$, or $10 \mu \mathrm{M}$ of $\mathrm{K}^{+}, \mathrm{Cd}^{2+}, \mathrm{Mg}^{2+}, \mathrm{Ca}^{2+}, \mathrm{Mn}^{2+}, \mathrm{Co}^{2+}, \mathrm{Na}^{+}, \mathrm{Cu}^{2+}, \mathrm{NH}_{4}^{+}, \mathrm{Hg}^{2+}, \mathrm{Ni}^{2+}, \mathrm{Fe}^{3+}, \mathrm{Pb}^{2+}, \mathrm{Fe}^{2+}$, and $\mathrm{Zn}^{2+}$ ions. Only with the $\mathrm{Cr}$ (III) concentration above $500 \mathrm{nM}$ did the band become strongly intensified at $563 \mathrm{~cm}^{-1}$. This may be due to unique Raman enhancements of EDTA-Cr(III) for metal-N stretching band on AgNPs. Since EDTA compounds are known to combine various ions, it is likely that the EDTA-ion complex may have a different interaction on AgNPs only in the case of $\mathrm{Cr}^{3+}$. According to the X-ray photoelectron spectroscopy (XPS) data, the atomic percentages of the EDTA complexes of $\mathrm{Cr}$ and $\mathrm{K}$ on AgNPs were measured to be $1.41 \%$ and $0.24 \%$, respectively. The relative percentages of $\mathrm{Cr}$ and $\mathrm{K}$ with respect to $\mathrm{Ag}$ were also found to be $3.93 \%$ and $0.77 \%$, respectively. For the case of the $\mathrm{Fe}^{3+}$ ion, we could not observe any iron species in the whole spectral region between 1000 and $0 \mathrm{eV}$. Our XPS data suggest that the $\mathrm{Cr}^{3+}$ ion may strongly adsorb on Ag surfaces in comparison with the other ions. These results suggest that the EDTA- $\mathrm{Cr}^{3+}$ complex may bind more strongly on AgNPs to lead to strong concentration-dependent SERS spectra. It can be interpreted that EDTA may show the carboxylate bands at lower concentrations of $\mathrm{Cr}$ (III) and the other ionic cases. At higher concentrations of $\mathrm{Cr}$ (III), the marker band of the $\mathrm{Cr}$ (III)-EDTA complex could be intensified in the SERRS spectra. Figure 4a shows concentration-dependent SERS spectra of detection of Cr(III) using AgNPs and tris-EDTA in the range of $0.005-10 \mu \mathrm{M}$. We found that the band at $563 \mathrm{~cm}^{-1}$ became stronger above $500 \mathrm{nM}$ in distilled water. The SERRS bands from 200 to $300 \mathrm{~cm}^{-1}$, which can be ascribed to Ag-N and Ag-COO, also showed different binding of the EDTA-Cr(III) complex on AgNPs. 


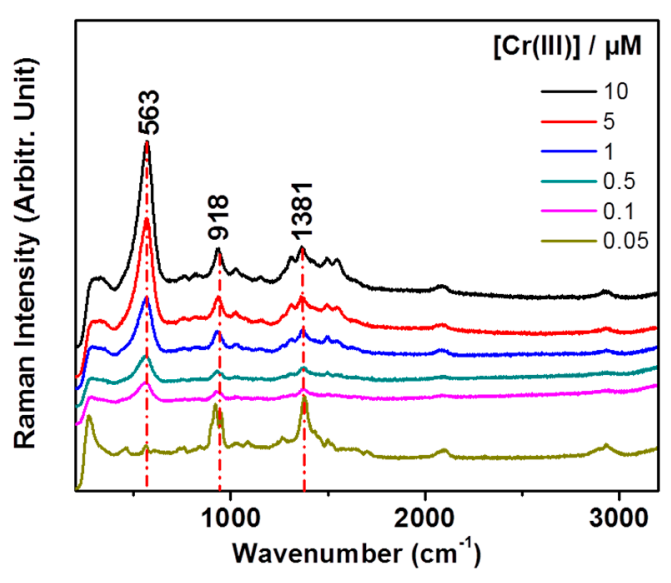

(a)

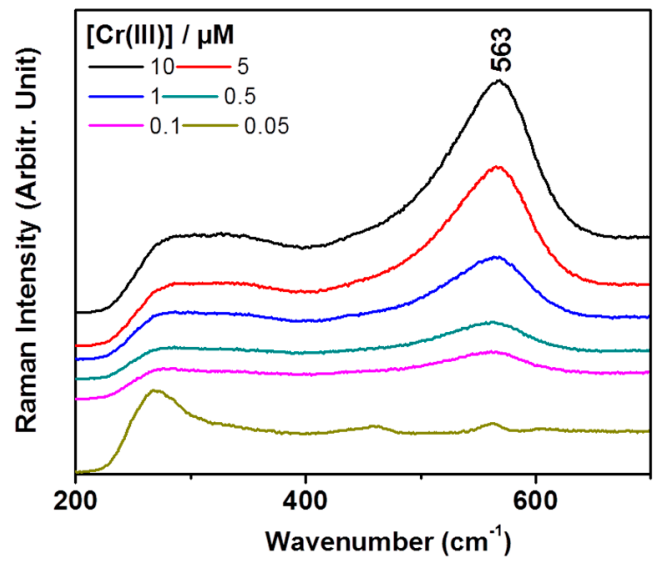

(b)

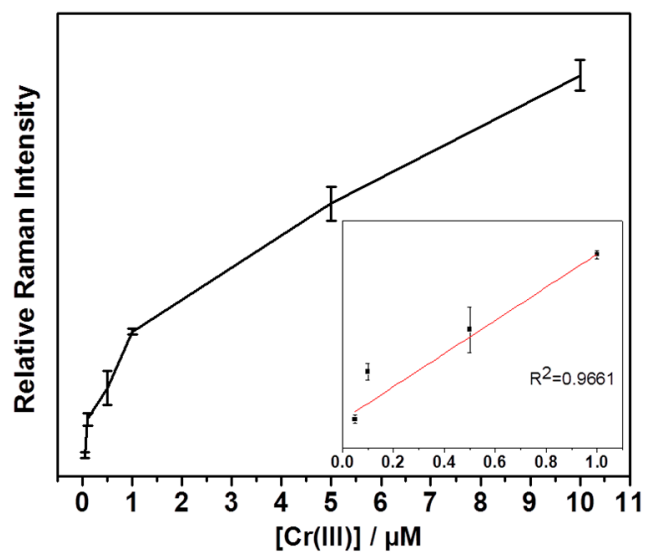

(c)

Figure 4. (a) Concentration-dependent SERS spectra using AgNPs and Tris-EDTA in the range of $0.005-10 \mu \mathrm{M}$ of $\mathrm{Cr}(\mathrm{III})$; (b) A magnified view of the vibrational bands between 200 and $750 \mathrm{~cm}^{-1}$ in the $\mathrm{Cr}$ (III) concentration-dependent SERS spectra; (c) A calibration curve of the vibrational band intensities at $\sim 563 \mathrm{~cm}^{-1}$ with respect to those at $\sim 918 \mathrm{~cm}^{-1}$. The inset shows a linear fitting result for the 0.05 and $1.0 \mu \mathrm{M}$ regions.

Based on these data, we attempted to detect $\mathrm{Cr}$ (III) by mixing seawater as proof of application. Table 1 shows the elemental compositions of the used seawater where $\mathrm{K}, \mathrm{Mg}, \mathrm{Ca}$, and $\mathrm{Na}$ ion concentrations were $\sim 13.3 \mathrm{mM}, \sim 43.6 \mathrm{mM}, \sim 8.61 \mathrm{mM}$, and $\sim 435 \mathrm{mM}$, respectively. We could clearly observe the marker band of $563 \mathrm{~cm}^{-1}$ to quantify $\mathrm{Cr}(\mathrm{III})$ concentrations as shown in Figure $5 \mathrm{a}$. Figure $5 \mathrm{~b}$ shows a calibration curve of the vibrational band intensities at $\sim 563 \mathrm{~cm}^{-1}$ depending on $\operatorname{Cr}(\mathrm{III})$ concentrations in the seawater sample. The detection limit is estimated to be as low as $500 \mathrm{nM}$.

Table 1. The element compositions of the tested water samples. (Unit in ppm (mg/L).)

\begin{tabular}{|c|c|c|c|c|c|c|c|c|c|c|c|c|c|c|}
\hline \multirow{2}{*}{ Sample } & \multicolumn{14}{|c|}{ Compositions } \\
\hline & $\mathbf{K}$ & Cd & Mg & $\mathrm{Ca}$ & Mn & Co & $\mathrm{Na}$ & $\mathbf{C u}$ & $\mathbf{H g}$ & $\mathrm{Ni}$ & $\mathrm{Fe}$ & $\mathbf{P b}$ & $\mathbf{Z n}$ & $\mathrm{Cr}$ \\
\hline Distilled & $\mathrm{ND} *$ & ND & ND & 0.03 & ND & ND & 1.05 & ND & ND & ND & ND & ND & ND & $\mathrm{ND}$ \\
\hline Seawater & 521.78 & ND & $1,059.81$ & 344.90 & 0.03 & ND & $10,001.92$ & 0.02 & ND & ND & ND & ND & 0.02 & ND \\
\hline
\end{tabular}

* ND stands for "Not Detected". Hg contents were determined by a mercury analyzer, whereas the rest of ions were tested by ICP-OES. 


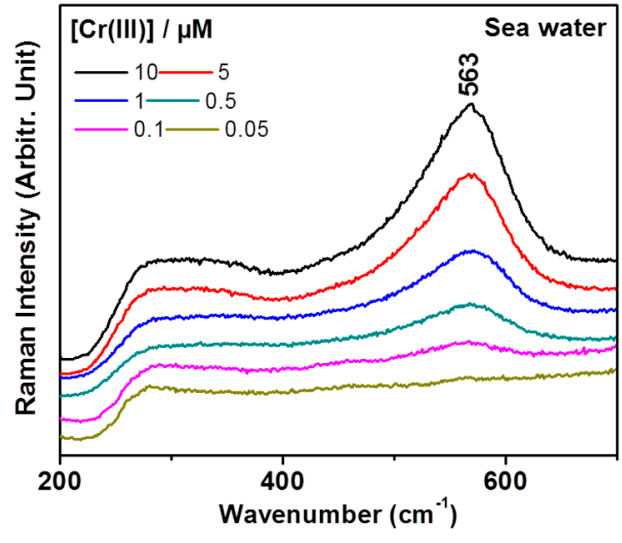

(a)

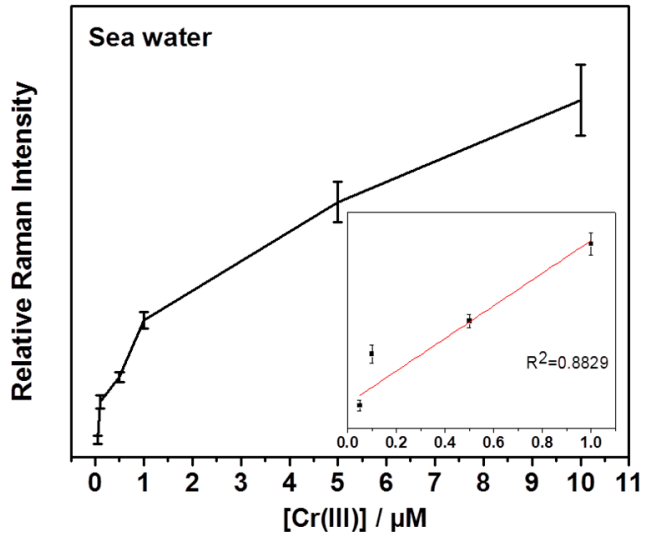

(b)

Figure 5. (a) Test of real seawater sample for the $\mathrm{Cr}$ (III) detection; (b) A calibration curve of the vibrational band intensities. Three independent measurements were performed to yield the standard deviations as marked in the error bars. The inset shows a linear fitting result for the 0.05 and $1.0 \mu \mathrm{M}$ regions.
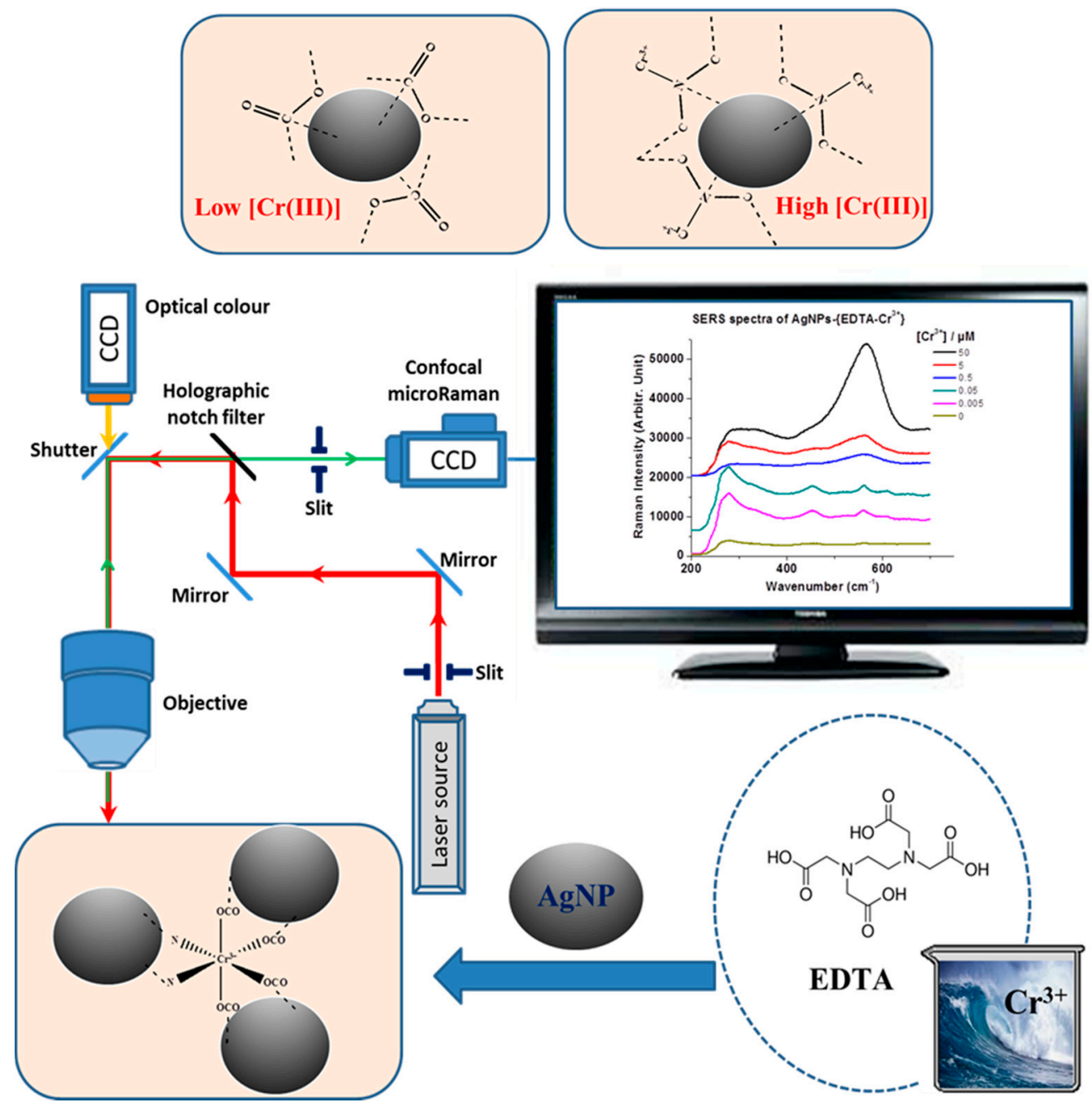

Figure 6. Schematic diagram of detection of Cr(III) using AgNPs. The carboxylic acid group of EDTA is expected to bind on AgNPs at low concentrations of $\mathrm{Cr}$ (III). As the $\mathrm{Cr}$ (III) increased, the intensified $\mathrm{Cr}$ (III)-N mode could be monitored by confocal SERRS. 
One of the possibilities of the characteristic Raman band enhancement mechanism is inducing a charge-transfer (CT) transition due to the combined molecule-metal interaction [32]. The energy levels of EDTA- $\mathrm{Cr}^{3+}$ and the Fermi level of Ag are resonating for a CT transition, while it is likely that the other EDTA-ion complexes seem not to have an efficient CT transition with Ag in this energy state.

Figure 6 shows a schematic diagram to detect the $\mathrm{Cr}$ (III) by means of confocal Raman spectroscopy. EDTA is first introduced to selectively bind $\mathrm{Cr}(\mathrm{III})$. On AgNPs, the SERRS spectra in the presence of $\mathrm{Cr}(\mathrm{III})$ above $500 \mathrm{nM}$ provide a method to discriminate and quantify $\mathrm{Cr}(\mathrm{III})$, despite the interference of $\mathrm{K}, \mathrm{Mg}, \mathrm{Ca}$, and $\mathrm{Na}$ ions in seawater samples. The adsorption geometries for low and high concentrations of $\mathrm{Cr}(\mathrm{III})$ were estimated to be different on the basis of Raman spectral features. The strong band at $\sim 563 \mathrm{~cm}^{-1}$ suggested a metal-N coordination at high concentrations of $\mathrm{Cr}$ (III). Our approach combined the use of SERRS to check the selectivity and sensitivity of the detection of $\mathrm{Cr}$ (III) in real seawater solutions.

\section{Conclusions}

We report a new approach for the submicromolar detection of $\mathrm{Cr}$ (III) ions using Tris-EDTA buffer and AgNPs. A quantitative trend down to the micromolar range was observed in the analysis of the spectroscopic changes depending on the $\mathrm{Cr}$ (III) concentrations. Tris-EDTA is sensitive and selective in binding chromium (III) in the presence of AgNPs. A detection limit as low as $500 \mathrm{nM}$ of $\mathrm{Cr}$ (III) could be achieved on the basis of SERS measurements. Seawater samples containing different chromium contents were also tested by means of Raman spectral change for a practical application of our methods. The EDTA-Cr(III) complex produced a prominent Raman peak at $\sim 563 \mathrm{~cm}^{-1}$ on AgNPs at concentrations of $\mathrm{Cr}$ (III) higher than $500 \mathrm{nM}$. Infrared spectroscopy also indicated a structural change of EDTA upon binding $\mathrm{Cr}$ (III), whereas UV-Vis absorption spectra suggested that there would be an electron transition at $\sim 600 \mathrm{~nm}$ for EDTA-Cr(III) complex and aggregation of AgNPs as the $\mathrm{Cr}$ (III) concentration increased. Considering that EPA regulatory limit of the $\mathrm{Cr}$ (III) ion for drinking water is around $1.9 \times 10^{-6} \mathrm{M}$, our method may be useful in detecting harmful wastewater by means of AgNPs and SERS. The EDTA-Cr(III) complex could yield different SERRS intensities on AgNPs. Raman spectroscopy is found to be sensitive and selective in binding Cr(III) with EDTA enhanced by AgNPs.

\section{Acknowledgments}

This work is supported by Soongsil University Research Fund.

\section{Author Contributions}

SJ and NHL conceptualized the study. NHL designed and conducted the experiments. SJ analyzed the data. All authors read and reviewed the manuscript.

\section{Conflicts of Interest}

The authors declare no conflict of interest. 


\section{References}

1. Aragay, G.; Pons, J.; Merkoci, A. Recent trends in macro-, micro-, and nanomaterial-based tools and strategies for heavy-metal detection. Chem. Rev. 2011, 111, 3433-3458.

2. Kim, Y.; Johnson, R.C.; Hupp, J.T. Gold nanoparticle-based sensing of "spectroscopically silent" heavy metal ions. Nano Lett. 2001, 1, 165-167.

3. Lee, H.; Xu, L.; Koh, D.; Nyayapathi, N.; Oh, K.W. Various on-chip sensors with microfluidics for biological applications. Sensors 2014, 14, 17008-17036.

4. Li, Z.; Jamal Deen, M.; Kumar, S.; Ravi Selvaganapathy, P. Raman spectroscopy for in-line water quality monitoring-Instrumentation and potential. Sensors 2014, 14, 17275-17303.

5. Holthoff, E.L.; Stratis-Cullum, D.N.; Hankus, M.E. A nanosensor for TNT detection based on molecularly imprinted polymers and surface enhanced Raman scattering. Sensors 2011, 11, 2700-2714.

6. Zhou, Q.; Zhang, X.; Huang, Y.; Li, Z.; Zhang, Z. Rapid detection of polychlorinated biphenyls at trace levels in real environmental samples by surface-enhanced Raman scattering. Sensors 2011, 11, 10851-10858.

7. Guerrini, L.; Rodriguez-Loureiro, I.; Correa-Duarte, M.A.; Lee, Y.H.; Ling, X.Y.; de Abajo, F.J.G.; Alvarez-Puebla, R.A. Chemical speciation of heavy metals by surface-enhanced Raman scattering spectroscopy: Identification and quantification of inorganic- and methyl-mercury in water. Nanoscale 2014, 6, 8368-8375.

8. Preuss, H.G.; Echard, B.; Perricone, N.V.; Bagchi, D.; Yasmin, T.; Stohs, S.J. Comparing metabolic effects of six different commercial trivalent chromium compounds. J. Inorg. Biochem. 2008, 102, 1986-1990.

9. Vincent, J.B.; Love, S.T. The need for combined inorganic, biochemical, and nutritional studies of chromium(III). Chem. Biodivers. 2012, 9, 1923-1241.

10. Moghadam, M.R.; Dadfarnia, S.; Shabani, A.M.H. Speciation and determination of ultra trace amounts of chromium by solidified floating organic drop microextraction (SFODME) and graphite furnace atomic absorption spectrometry. J. Hazard. Mater. 2011, 186, 169-174.

11. Karak, D.; Banerjee, A.; Sahana, A.; Guha, S.; Lohar, S.; Adhikari, S.S.; Das, D. 9-Acridone-4carboxylic acid as an efficient $\mathrm{Cr}$ (III) fluorescent sensor: trace level detection, estimation and speciation studies. J. Hazard. Mater. 2011, 188, 274-280.

12. Sanchez-Moreno, R.A.; Gismera, M.J.; Sevilla, M.T.; Procopio, J.R. Potentiometric screen-printed bisensor for simultaneous determination of chromium(III) and chromium(VI). Electroanalysis 2011, 23, 287-294.

13. Zhou, Y.; Li, Y.S.; Meng, X.Y.; Zhang, Y.Y.; Yang, L.; Li, Z.H.; Zhang, J.H.; Wang, X.R.; Liu, J.Q.; Lu, S.Y.; et al. Production of a monoclonal antibody and development of an immunoassay for detection of Cr(III) in water samples. Chemosphere 2013, 93, 2467-2472.

14. Ye, Y.; Liu, H.; Yang, L.; Liu, J. Sensitive and selective SERS probe for trivalent chromium detection using citrate attached gold nanoparticles. Nanoscale 2012, 4, 6442-6448. 
15. Zhang, H.; Liu, Q.; Wang, T.; Yun, Z.; Li, G.; Liu, J.; Jiang, G. Facile preparation of glutathione-stabilized gold nanoclusters for selective determination of chromium(III) and chromium(VI) in environmental water samples. Anal. Chim. Acta 2013, 770, 140-146.

16. Sun, J.; Zhang, J.; Jin, Y. 11-Mercaptoundecanoic acid directed one-pot synthesis of water-soluble fluorescent gold nanoclusters and their use as probes for sensitive and selective detection of $\mathrm{Cr}^{3+}$ and $\mathrm{Cr}^{6+}$. J. Mater. Chem. C 2013, 1, 138-143.

17. Dang, Y-Q.; Li, H-W.; Wang, B.; Li, L.; Wu, Y. Selective detection of trace $\mathrm{Cr}^{3+}$ in aqueous solution by using 5,5'-dithiobis (2-nitrobenzoic acid)-modified gold nanoparticles. ACS Appl. Mater. Interfaces 2009, 1, 1533-1538.

18. Hughes, S.I.; Dasary, S.S.R.; Singh, A.K.; Glenn, Z.; Jamison, H.; Ray, P.C.; Yu, H. Sensitive and selective detection of trivalent chromium using hyper Rayleigh scattering with 5,5'-dithio-bis-(2nitrobenzoic acid)-modified gold nanoparticles. Sens. Actuators B Chem. 2013, 178, 514-519.

19. Chen, M.; Cai, H-H.; Yang, F.; Lin, D.; Yang, P-H.; Cai, J. Highly sensitive detection of chromium(III) ions by resonance Rayleigh scattering enhanced by gold nanoparticles. Spectrochim. Acta 2014, 118A, 776-781.

20. Singh, A.; Kaur, S.; Kaur, A.; Aree, T.; Kaur, N.; Singh, N.; Bakshi, M.S. Aqueous-phase synthesis of copper nanoparticles using organic nanoparticles: Application of assembly in detection of $\mathrm{Cr}^{3+}$. ACS Sustainable Chem. Eng. 2014, 2, 982-990.

21. Liang, J.; Liu, H.; Lan, C.; Fu, Q.; Huang, C.; Luo, Z.; Jiang, T.; Tang, Y. Silver nanoparticle enhanced Raman scattering-based lateral flow immunoassays for ultra-sensitive detection of the heavy metal chromium. Nanotechnology 2014, 25, 495501.

22. Wang, H.; Wu, G. The monothiocyanate complexes of chromium ion(III) on the silver electrode by the surface enhanced Raman scattering. Spectrochim. Acta 2005, 62A, 415-419.

23. Cao, D.; Fan, J.; Qiu, J.; Tu, Y.; Yan, J. Masking method for improving selectivity of gold nanoclusters in fluorescence determination of mercury and copper ions. Biosens. Bioelectron. 2013, 42, 47-50.

24. Fahnestock, K.J.; Manesse, M.; McIlwee, H.A.; Schauer, C.L.; Boukherroub, R.; Szunerits, S. Selective detection of hexachromium ions by localized surface Plasmon resonance measurements using gold nanoparticles/chitosan composite interfaces. Analyst 2009, 134, 881-886.

25. Kanamori, K.; Kawai, K. Raman spectral study on the solution structure of the chromium(III)-EDTA complex. Inorg. Chem. 1986, 25, 3711-3713.

26. Krishnan, K.; Plane, R.A. Raman spectra of ethylenediaminetetraacetic acid and its metal complexes. J. Am. Chem. Soc. 1968, 90, 3195-3200.

27. Wagner, C.C.; Baran, E.J. Vibrational spectra of two Fe(III)/EDTA complexes useful for iron supplementation. Spectrochim Acta 2010, 75A, 807-810.

28. Singh, D.K.; Ganbold, E-O.; Cho, E-M.; Cho, K-H.; Kim, D.; Choo, J.; Kim, S.; Lee, C.M.; Yang, S.I.; Joo, S-W. Detection of the mycotoxin citrinin using silver substrates and Raman spectroscopy. J. Hazard. Mater. 2014, 265, 89-95.

29. Cong, V.T.; Ganbold, E-O.; Saha, J.K.; Jang, J.; Min, J.; Choo, J.; Kim, S.; Song, N.W.; Son, S.J.; Lee, S.B.; et al. Gold nanoparticle silica nanopeapods. J. Am. Chem. Soc. 2014, 136, 3833-3841. 
30. Wheeler, W.D.; Legg, J.I. Solution structure of the chromium(III) complex with EDTA by deuteron NMR spectroscopy. Inorg. Chem. 1984, 23, 3798-3802.

31. Socrates, G. Infrared Characteristic Group Frequencies-Tables and Charts, 2nd ed.; John Wiley and Sons Ltd.: Chichester, UK, 1994.

32. Lombardi, J.R.; Birke, R.L. A unified view of surface-enhanced Raman scattering. Acc. Chem. Res. 2009, 42, 734-742.

(C) 2015 by the authors; licensee MDPI, Basel, Switzerland. This article is an open access article distributed under the terms and conditions of the Creative Commons Attribution license (http://creativecommons.org/licenses/by/4.0/). 